\title{
A formação universitária como bem público
}

\author{
Maria Luísa Bissoto \\ Centro Universitário Salesiano de São Paulo \\ Maria Luiza Vechetin Begnami \\ Centro Universitário Hermínio Ometto
}

\section{Resumo}

Estado neo liberal traz consequências para a integridade das instituições sociais e as do ensino superior. Objetiva-se analisar uma consequência em especial: a corrosão da ideia de bem público, abarcando questões de justiça social e de equanimidade. Considera-se como a formação universitária é afetada por essa corrosão e o papel da Universidade na sua reconstrução. Metodologicamente, está fundamentada na perspectiva da ética do cuidado, no âmbito da Teoria Histórico-Cultural da Atividade. Tais bases teóricas favorecem a (re)interpretação epistemológica do fazer pedagógico universitário, propondo que a Universidade encontre sua razão de ser imiscuída nas questões essenciais do seu tempo.

Palavras-chave: Teoria histórico-cultural da atividade. Educação universitária. Formação humanista.

\section{The University educationas a public good}

\section{Abstract}

The neoliberal State produces consequences for social integrity of institutions and higher education. The objective here is to analyze a result in particular: the corrosion of the idea of public good, covering social justice and equality issues. It is considered how university education is affected by this corrosion and the role of the university in its reconstruction. Methodologically, it is based in the ethics of care perspective, under the Cultural-Historical Activity Theory. Such theoretical bases favor the (re) interpretation of the university teaching epistemology, proposing that the university find their reason for being meddled in the major issues of his time.

Keywords: Cultural-Historical Activity Theory. University education. Human isteducation. 


\section{La educación universitaria como un bien público}

\section{Resumen}

El Estado neoliberal tiene consecuencias para la integridad de las instituciones sociales y educación superior. Pretendemos analizar un resultado particular: la corrosión de la idea de bien público, abarcando la justicia social y la igualdad. Consideramos como la educación universitaria es afectada por esta corrosión y el papel de la universidad ensure construcción. Metodologicamente, nos basamos en la perspectiva de la ética del cuidado, bajo la teoría de la actividad Histórico Cultural. Tales bases teóricas favorecen la (re)interpretación epistemológica a docencia universitaria, proponiendo que la universidad encuentre su razón de ser inmiscuida en los principales problemas de su tiempo.

Palabras-clave: Teoría de la actividad histórico-cultural. Educación universitaria. Educación humanista.

\section{Introdução}

Inúmeras transformações econômicas, sociais, políticas e tecnológicas têm desencadeado, nas últimas duas décadas, problemáticas novas na maneira de se viver em sociedade.Considera-se que, a partir de 1989, a sociedade ocidental entra em uma nova crise, gerada pela passagem de um modelo de modernidade societária, caracterizado por uma lógica econômica, política e sociocultural focada numa dimensão nacional e esgarçamento de fronteiras identitárias (MAGATTI,2005). E que aparece evidenciado na desterritorialização e na fragmentação da produção de bens, na mobilidade do capital, na internacionalização da economia e nas relações de poder estabelecidas entre países, no surgimento de blocos econômico-políticos, como o Mercosul e a União Europeia, por exemplo, bem como nas possíveis rupturas com formas de construção e divulgação do conhecimento, e com sistemas de crenças e valores ético-morais, favorecida pelo crescente desenvolvimento dos recursos tecnológicos e de acesso à informação.

Esses fenômenos são, geralmente, agrupados sob o rótulo de "globalização", definida como o processo de internacionalização da produção, com uma nova divisão, internacional, do trabalho, pautada por uma ideologia de poder econômico neoliberal. Comporta, dentre outros, importantes 
movimentos migratórios, das regiões mais pobres para aquelas onde passa haver maior concentração de riqueza, e, destacadamente, a transformação na natureza filosófico-política dos Estados, que se transformam em agências fomentadoras desse processo, numa minimização do estado de bem-estar social (COX, 1996). E, como aqui argumentado, num esgotamento da ideia de bem público, entendido por Nixon (2012), não como a somatória dos interesses individuais presentes num determinado grupo social, mas, contrariamente, com preocupações que envolvem questões de equanimidade e justiça social. Magatti (2005) assevera que a característica central da modernidade contemporânea está representada numa condição global de rompimento com formas de se pensar o mundo e a vida, em suas relações, imbricada aos novos contornos econômicos e tecnológicos. Há a difusão de ideologias que parecem engessar ações de coletivismo e de solidariedade, exacerbando o individualismo, a "tecnificação" do viver social e o agravamento da marginalização e das desigualdades sociais. Isso pode ser observado em dados de documentos internacionais, como no relatório elaborado pelo Observatório de Desigualdades (2014), apontando que as desigualdades sociais nos países ocidentais, a partir da década de 1990, se mantiveram elevadas, ou

111 se acentuaram, mesmo naqueles países onde houve melhoria nas condições econômicas, como é o caso dos chamados países emergentes: Brasil, Rússia, Índia, China e África do Sul (SILVÉRIO, 2014$).$

Os impactos dessa nova condição global nas sociedades são difusos e deletérios, difíceis de ser atribuídos a fatores causais isolados, e sua gravidade está associada à capacidade de enfrentamento e de resistência que os diferentes setores sociais conseguem desenvolver, nesse cenário. Três impactos são mais centrais e perniciosos: a desregulamentação estatal, que tem, como efeitos, uma crescente privatização dos serviços públicos,e, sobretudo,a infiltração do crime organizado nos espaços não ocupados pelo Estado; a fragmentação da vida social e a perda da capacidade discursiva e dialógica para a resolução de conflitos, num incremento da radicalização de posições extremistas; e a mediatização da ideologia dominante, neoliberal, que se encontra intrínseca nos fundamentos da globalização, graças à instrumentalidade dos recursos tecnológicos e de comunicação em massa (HESPANHA, 1986).

Os desdobramentos desses impactos têm repercussões importantes em todas as esferas do viver social, incluindo as instituições de ensino superior, para as quais a sociedade se volta, demandando dessas instituições, enquanto lócus 
histórico de discussão e geração de novas ideias e conhecimentos, ações e possibilidades de resposta para os dilemas postos à vida contemporânea, decorrentes desse novo contexto. No entender de Natale, Libertella e Hayward (2001), tais demandas têm modificado a relação dessas instituições com a própria sociedade e também, de maneira importante, com a produção do conhecimento em si. Os conhecimentos práticos, técnicos, funcionais, aparecem crescentemente valorizados, junto à pressão para formar profissionais com as habilidades, consideradas necessárias ao mercado do trabalho.Isso impele as instituições de ensino superior a optar por currículos, metodologias de ensino e tratamento do conhecimento que atendam aos requerimentos tecnológicos, à "praticidade imediata", às políticas econômicas ou às necessidades das corporações mercantis, em detrimento da formação humanista, sobre a qual a universidade se fundou.

Outro tipo de pressão reside na premência de que as instituições de ensino superior, independente da sua natureza jurídica (públicas, particulares, comunitárias), assumam crescente "espírito empreendedor" (GOOD, 2001 ). Assim, se revela, por exemplo, no incentivo à captação de recursos para sua manutenção e desenvolvimento de projetos e pesquisas, junto a organismos públicos e/ou à iniciativa privada, com pouca discussão em relação às questões éticas envolvidas no financiamento do custeio da produção do saber. Ou a quem, ou a que, este se destina.Dessa forma, o autor reitera a concepção de que:

A ideia liberal humanista de Universidade é basicamente a de um colegiado; consiste de uma comunidade de individualidades agrupadas pelo amor ao aprender. Este ideal está agora sendo recolocado por um novo conceito: um sistema de serviços de informação, direcionados para categorias de clientes, e projetos coletivos de pesquisa. A dupla autonomia da universidade liberal - a autonomia da instituição do controle governamental, das corporações mercantis, ou da pressão de outros tipos de grupos, ea liberdade individual do professor em relação a pressões conformadoras no âmbito da universidade- está sendo erodida. $\bigcirc$ caráter distinto da Universidade, o sentido de que esta é uma organização diferente de outras organizações, também está esvanecendo. Gradualmente, a linguagem, o estilo e as estruturas empresariais estão sendo importadas para o mundo acadêmico [...]. A Universidade liberal está se transformando em Universidade empresarial (GOOD, 2001, p. 103). 
As instituições de ensino superior se mostram, progressivamente, mais envolvidas em buscar conciliar uma pluralidade de interesses: os daqueles sujeitos que as procuram demandando a aquisição de conhecimentos e habilidades que favoreçam a empregabilidade; dos empregadores, que esperam que essas instituições formem profissionais capacitados; e por forças políticas e econômicas que procuram representatividade, suporte técnico e intelectual, bem como o aval acadêmico, para o planejamento de suas ações. No âmbito dessa emergente configuração das relações entre instituições de ensino superior e sociedade, uma questão central é: quais os significados que podem ser, então, atribuídos à educação? $E$, concomitantemente, qual é a missão a ser assumida, na contemporaneidade, por essas instituições?

Numa tentativa de respondera essa questão, Bok (1982) argumenta com base em três considerações: a. quão importantes são as necessidades da sociedade e como as instituições de ensino superior podem atendê-las; b. como tais necessidades vêm sendo definidas, por quem, e se há conflitos de interesse ou questões ético-morais que inviabilizem o envolvimento dessas instituições com tais necessidades e quais os efeitos que a atenção a essas necessidades terão sobre as instituições de ensino superior, como um todo.

$\mathrm{Na}$ argumentação desenvolvida neste artigo, entende-se que a principal missão das instituições de ensino superior, atualmente, é que elas se constituam como espaços de resistência e de organização da sociedade, para atender às situações de corrosão do conceito de bem público, como anteriormente definido. Em concordância com as considerações postas por Bok (1982), parte-se da perspectiva de que as instituições de ensino superior devem continuamente indagar, e promover a indagação, sobre quais são as necessidades dos grupos e populações que compõem determinada sociedade, como estas estão sendo (ou não) problematizadas, por quem, quais ações estão sendo tomadas para atendê-las, visando a que interesses, e propondo a construção de conhecimentos que favoreçam um viver equânime, pautado pelos parâmetros de justiça social. Isso remete a se pensar o fazer das instituições de ensino superior, em todas as suas vertentes, gestão, ensino, pesquisa e extensão, como atividade socialmente responsável. Obviamente, não no sentido mercantilista que o termo "responsabilidade social", vem assumindo na atualidade, mas no âmbito de uma ética do cuidado.

Como proposto, originalmente, por Giligan (1982), a ética do cuidado tem suas raízes teóricas em estudos sobre o feminismo, foco que, nas duas últimas décadas, vem sendo ampliado para outras esferas de análise social. 
seu fundamento central consiste em uma proposição no campo da ética na concepção da realidade como uma rede de relações, na qual nos sentimos, ou deveríamos nos sentir, imersos. De tal imersão emerge a sensibilidade empática e a ideia de responsabilidade para com o bem estar uns dos outros.

Essa premissa de conectividade entre os seres humanos é fundamental para o respeito aos direitos humanos e para a construção de uma sociedade pautada na justiça social. Não significa, como enganosamente pode parecer, uma proposição que pretenda a anulação dos conflitos. Seria ingenuidade supor que todas as relações humanas transcorrem em beatitude, com base no cuidado com o outro. Contudo, o ponto argumentativo dos teóricos desse novo campo é o de que esforços devem ser postos na preservação da "saúde" dos relacionamentos interpessoais, base da tessitura social. Isso envolve a escuta empática do outro, fomentando a resistência à mercantilização da vida em comum, em que as relações entre as pessoas são vistas como uma transação, como uma interação de troca, na qual alguém deve sair ganhando (HELD, 2006).

Críticas à proposição da ética do cuidado têm se dirigido a questionar o viés de "abnegação", que parece advir ao defender-se uma ética voltada para relações pessoais caracterizadas pela compaixão, altruísmo, simpatia e amor, como virtudes centrais. Contudo, como observa Giligan (1982), os pressupostos da sua abordagem não negligenciam o cuidado dos sujeitos para eles próprios: o agente moral deve sempre buscar equilibrar o cuidado individual com aquele voltado para os demais. Nas fases propostas pela autora, evidencia-se esta posição:

\section{Quadro 1}

\section{Estágios da ética do cuidado}

\begin{tabular}{|c|c|c|}
\hline \multicolumn{3}{|c|}{ Estágios da ética do cuidado } \\
\hline Faixa etária & Estágio & Objetivo \\
\hline Não indicada & Pré-convencional & Sobrevivência individual \\
\hline \multicolumn{3}{|c|}{ Transição do egoísmo para a responsabilidade para com outros } \\
\hline Idem & Convencional & Autosacrifício $=$ bondade \\
\hline \multicolumn{3}{|c|}{ Transição da bondade para a verdade - também somos pessoas } \\
\hline Talvez nunca & Pós-convencional & $\begin{array}{l}\text { Princípio da não violência - em relação } \\
\text { aos outros e a si próprio }\end{array}$ \\
\hline
\end{tabular}

Fonte | Giligan (1982) 
A formação universitária como bem público

A ética do cuidado pode ser colocada como embasamento para fomentar a reflexão sobre a responsabilidade social, que cabe às instituições de ensino superior na contemporaneidade:

Giligan propõe a ética do cuidado como responsabilidade social, desde a qual se almeja a busca pelo bem estar das pessoas $[\ldots]$ até uma proposta por uma segunda voz, que advoga a favor das diferenças, pelo reconhecimento de histórias particulares, pelo cuidado e o desejo para com o bem estar do outro, pela benevolência como matriz das relações sociais e do juízo ético (GARCÍA, 2004, p. 04).

Para as autoras deste artigo, instituições de ensino superior socialmente responsáveis se caracterizam como aquelas que discutem, em todos os seus âmbitos, os efeitos de suas ações para com a comunidade, seja interna ou externa, direcionando seus esforços didático-pedagógicos e de gestão para a construção de uma realidade mais equânime e socialmente justa, educando, desta forma, para que se estabeleça, entre o fazer universitário e o entorno social, integração das relações de cuidado. Nesse sentido, entende-se que a educação universitária constitui-se, primariamente, como um bem público.

Essas posições se contrapõem ao instrumentalismo que parece vigorar na formação universitária em tempos de globalização neoliberal; visando reduzir o caráter de coletividade das instituições de ensino superior à produção do "capital humano necessário" ao desenvolvimento econômico.

Esperando contribuir para a discussão do ensino superior como bem público, no sentido acima exposto, propõe-se, como argumento central deste artigo, que a formação do estudante universitário seja concebida enquanto atividade, no contexto da Teoria Histórico-Cultural da Atividade, como pensada por Vigotski e Leontiev e, depois, por Engëstrom. Tal teoria concebe a atividade humana como processo cultural e sócio-histórico, móvel da imbricação ser humano-entorno, constituindo-se como a essência da formação da consciência individual e social. Mostra-se, assim, uma relevante unidade de análise metodológica, pois permite conservar o foco na importância da subjetividade, concomitantemente ao caráter coletivo do viver humano.

$\bigcirc$ presente trabalho está assim organizado. Primeiramente, discutem-se concepções epistemológicas presentes no âmbito do ensino superior contemporâneo, considerando a limiłação dos processos didático-pedagógicos centrados na compreensão do conhecimento como neutro, anhistórico, 
ou como commodities. Defendem-se, então, mudanças nessas concepções, propondo-se que a formação universitária seja perspectivada pela Teoria Histórico-Cultural da Atividade, discutindo-se seus pressupostos. Considera-se que a construção dos saberes deve ser entendida como atividade eminentemente sócio-histórica, fundamental para a viabilidade do viver humano. Por fim, num aprofundamento da argumentação, a formação no ensino superior é analisada como atividade "expansiva", entendida como aquela que promove a ampliação dos modos de agir e de pensar, estimulando a inovação e a criatividade (ENGESTRÖM, 1999). E, no contexto deste trabalho, dentro da lógica de uma ética do cuidado e do bem público.

\section{Refletindo sobre concepções epistemológicas e questões didático- pedagógicas no ensino superior}

As bases epistemológicas no ensino superiores mostram herdeiras das tradições epistemológicas positivista e cartesiana, marcadas, de forma geral, pela prescrição de certezas, de fragmentação dos saberes, de racionalidade instrumental e da ideia de neutralidade dos conhecimentos, bem como do caráter anhistórico desses (LINGARD; NIXON; RANSOM, 2008). Tal herança pode obstaculizar a mudança de perspectivas e que conhecimentos precisam ser produzidos no e pelo mundo acadêmico, para quem e para quais objetivos. Ademais,em sociedades pautadas pela globalização neoliberal, a ideologia de produção de conhecimento está perpassada pelo viés capitalista, que privilegia a economia do conhecimento: o saber direcionado para a lucratividade, amarrada à formação do sujeito como capital humano e a aprendizagem ao longo da vida podendo significar a perpetuação dessa formação (WALKER; NIXON, 2004).

Em relação ao ensino, essas influências acabam por modelar as atividades didático-pedagógicas, que sofrem um acanhamento em sua função maior, isto é, de uma formação humanista integral, cerne da formação do ensino superior desde a criação das universidades. $\bigcirc$ conhecimento é tratado como blocos de informações, que podem ser transmitidas, absorvidas, ou possuídas pelos sujeitos que adquirem o direito de usá-las como bem pessoal, tendendo à alienação em sua relação com a sociedade. A problematização quanto às demandas sociais, as possibilidades de as instituições de ensino 
superior atenderem a estas, de que forma, e aos pressupostos éticos que devem vigorar na interação entre a produção de saberes, de recursos científico-tecnológicos e o viver humano, fica deslocada para planos secundários.

Parecem existir, em última análise, duas realidades diferentes: aquela das instituições de ensino superior, detentoras das prerrogativas de gerir a produção, disseminação e uso do conhecimento e o restante da sociedade;e a grande questão reside em como promover a integração entre ambas, como se as instituições de ensino, dentre elas, as de ensino superior, não tivessem emergido e vigorassem pelos modos como a sociedade se constituiu. Boaventura de Souza Santos faz uma afirmação que leva a refletir sobre o entendimento das ações universitárias e a sociedade:

[...] configurações cada vez mais complexas de saberes, a legitimidade da universidade só será cumprida quando as actividades, hoje ditas de extensão, se aprofundarem tanto que desapareçam enquanto tais epassem aser parte integrante das actividades de investigação eensino (SANTOS, 1999, p. 194).

Para que as relações entre sociedade e instituições de ensino supe117 rior se equilibrem, em termos de domínio quanto ao poder da produção e disseminação do saber, se faz necessário que tais instituições discutam outros paradigmas quanto à constituição do conhecimento, bem como de conceber o ensinar. $\bigcirc$ que passa pela ênfase no ensino como problematização do viver social é a dúvida como referência pedagógica, e o aluno como protagonista da ação educativa. Enfoca-se assim, o conhecimento a partir de sua produção histórica, tratando-o de forma interdisciplinar, mediando pontes entre saberes, atribuindo valores éticos aos objetivos acadêmicos. Dessa maneira, favorece a formação da consciência individual e coletiva e o modo e tipo de conhecimentos, gerados nas instituições de ensino superior, configurados por concepções de como a realidade se constitui e de como ela pode ser apreendida, dominada, transformada.

É preciso discutir fundamentalmente, no ensino superior, que a produção do conhecimento não está isenta de interesses, tampouco despojada de vaidades. Pelo contrário, é um espaçode uma luta concorrencial pelo poder, nesse caso, daquele compreendido como a capacidade de agir e falar de forma legítima e autoritária (BOURDIEU, 1989). Isso implica reconhecer que a questão pedagógica do ensinar e aprender, no ensino superior, se referência 
num mapeamento epistemológico, decorrente de influências de poder, presentes na sociedade.

A contraposição às ideias do conhecimento como commodities, como descontextualizados da realidade social, avançando para uma concepção do conhecer que assevera a não neutralidade deste, sua intrínseca intencionalidade, assim, pródigo de valores ético-morais, e que concebe a ciência como um ato humano, historicamente situado, requer uma nova relação entre sociedade e instituições de ensino superior,coadunando-se,assim com as posições assumidas pela Teoria Histórico-Cultural da Atividade, conforme explicitado abaixo.

Abordar o ensino superior como espaço de fomentar o bem público representa um compromisso contínuo com uma formação humanista, o que não se restringe aos aspectos didático-pedagógicos, mas se estende à própria configuração identitária da universidade, devendo priorizar, em suas políticas internas e externas, objetivos e missão, a preocupação e o engajamento numa ética do cuidado. Assumir tal compromisso representa fortalecer o papel das instituições de ensino superior como espaços essenciais para a reflexão e a resistência aos modelos de globalização neoliberal, que parecem conformar as sociedades, contemporaneamente. Não configura, porém, uma tarefa fácil, pelas considerações anteriormente levantadas. Requer o debate de outras possibilidades de se perspectivar o que-fazer educacional nesse nível de ensino.

Argumenta-se que enfocar a formação do estudante como atividade, no âmbito das teorizações propostas por Leontiev e também por Engeström, pode levar ao delineamento de propostas educacionais mais favoráveis a um pensar sistêmico, que alinhe a formação científica e tecnológica, à sensibilidade ética para com as necessidades do outro e da comunidade e à curiosidade epistêmica necessária ao perspectivar a realidade de maneira socialmente problematizadora.

\section{Teoria histórico-cultural da atividade: possibilidades de mudanças conceituais no ensino superior}

A Teoria Histórico-Cultural da Atividade, concebida por Vigotski e Leontiev na década de 1920 e, posteriormente, pesquisada por seus seguidores, Davydov, Galperin, Elkonin e Engëstrom, dentre outros, compõe-se de 
um conjunto de conceitos que têm, por cerne, a ideia de que a vida humana se desenrola no âmbito de atividades direcionadas a objetivos, socialmente compartilhados, em sua natureza. A partir desse ponto, busca-se compreender e explicar como e por que as atividades humanas são executadas, a importância de se compreender os processos de construção da significação destas, considerando o papel dimensionador assumido pelo contexto, pelo ambiente social e cultural. A concepção de objeto da atividade é central nesta perspectiva teórica, e representa um horizonte de possibilidades: um projeto coletivo, carregado de conflitos, que é estabilizado pelo compartilhamento de ferramentas, signos, discussão de valores e procedimentos. Necessidades, emoções e sentimentos, tanto em nível individual como coletivo, permeiam os objetos le objetivos) da atividade,e compõem a quadratura dos parâmetros contextuais nos quais a atividade é tramada.

Na concepção de Leontiev (1974), a atividade modela a consciência humana, e é a substância da nossa consciência. Tal entendimento é tributário daquele asseverado pelo materialismo histórico-dialético, que, contrariando posições idealistas, que concebem a atividade humana como abstração, coloca-a inversamente, como emergindo da concretude dos embates entre o

119 homem e a natureza.

autor assim define a atividade:

A atividade - em seu sentido genérico - é a unidade molar, não aditiva, da vida do sujeito material, corpóreo. Em um sentido mais estrito (isto é, ao nível psicológico), é a unidade da vida que é mediada pela reflexão mental. A função real desta unidade é orientar o sujeito no mundo dos objetos. Em outras palavras, a atividade não é uma reação ou um agregado de reações, mas um sistema com sua própria estrutura, sua própria transformação interna, seu próprio desenvolvimento (LEONTIEV, 1979, p. 46).

A atividade, então, se constitui não como algo em si intrinsecamente material, ou ideal, mas como um processo de transição entre uma exterioridade, o modo de configurar e sistematizar o agir humano no mundo real, posto por uma determinada sociedade ou grupo social, e a interioridade dos processos psicológicos humanos, compondo a indissociabilidade da unidade mundo-sujeito.

Enquanto processo, a atividade se compõe dos seguintes elementos, que formam sua macroestrutura: sujeito (indivíduo ou grupo), objeto/motivo, ações e operações. $\bigcirc$ sujeito age de forma direcionada a um objeto, motivado 
pelo seu envolvimento com a materialidade do entorno; produto do agir social, coletivo, tensional, dos seres humanos para a transformação do mundo natural. Tal objeto/motivo, ao mesmo tempo que está na origem da atividade do sujeito, se desenvolve por meio dela.

Afirmar que o objeto da atividade é seu motivo significa postular que este é o que dá à atividade uma orientação consciente e específica, ou seja que a atividade deve permitir que seja atendida. Em termos do educar para o bem público trata-se de descobrir como colocar a ética do cuidado como objeto central da atividade educativa no ensino superior.

Considerando os demais elementos da atividade, pode-se dizer que a ação caracteriza um subprocesso, de curta duração, estruturado e subordinado por uma representação mental do resultado a ser alcançado, e que se realiza por meio de operações procedimentais, que podem se tornar habituais com a prática (LEONTIEV, 1974). A atividade é, portanto, caracterizada por ações dirigidas a objetos, desempenhada pelo sujeito e outros possíveis sujeitos envolvidos na atividade. $\bigcirc$ resultado como um todo deve satisfazer a necessidade do sujeito ou do grupo, mesmo que cada membro deste tenha se dedicado, apenas, a uma parte específica da atividade. Os elementos da atividade, conquanto possam ser analisados individualmente, não devem ser percebidos como separados, ou seja, é preciso levar em conta as relações internas que os caracterizam e também as relações entre eles, de modo a não perder sua complexidade.

É por meio da atividade, assim, compreendida, que os processos cognitivos humanos se desenvolvem no âmbito de uma epistemologia materialista histórica. Cada sujeito, em particular, se apropria dos instrumentos e signos criados histórica e socialmente, gerados e significados pela atividade, ressignificando-os. Nesse sentido, pensando nas implicações que essa concepção de atividade tem para a questão da educação, Leontiev afirma:

As aquisições do desenvolvimento histórico das aptidões humanas não são simplesmente dadas aos homens nos fenômenos objetivos da cultura material e espiritual que os encarnam, mas são aí apenas postas. Para se apropriar destes resultados, para fazer deles as suas aptidões, 'os órgãos da sua individualidade', a criança, o ser humano, deve entrar em relação com os fenômenos do mundo circundante através de outros homens, isto é, num processo de comunicação com eles. Assim, a criança aprende a atividade adequada. Pela sua função este processo é, portanto, um processo de educação (LEONTIEV, 1974, p. 290, destaques no original). 
Engeström (1999; 1999a), tomando por base os estudos dos pensadores seminais da Teoria Histórico-Cultural da Atividade, vem propondo uma formulação diferenciada. Partindo da concepção de que a característica central da atividade reside em sua natureza coletiva, Engeström postula que a atividade se constitui num sistema, um todo integrado e indivisível, estruturado em cinco elementos: comunidade, regras, divisão do trabalho, sujeito, objeto e ferramentas culturais, como demonstrado na Figura abaixo:

\section{Figura 1}

\section{Modelo geral de um sistema de atividade}

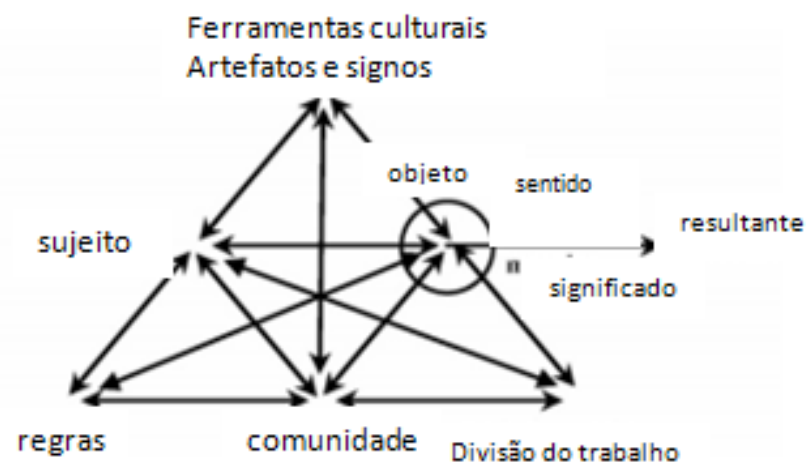

Fonte |Engeström eSannino (2010)

A comunidade é formada por todas as pessoas que possuem interesse na atividade, que compartilham o mesmo objeto/motivo coletivo; as regras sociais são representadas pelas normas e convenções estabelecidas dentro da comunidade e a divisão do trabalho se refere à forma de organização de uma comunidade relacionada ao processo de transformação de um objeto em um resultado, com processos horizontais para a distribuição das tarefas e verticais, na divisão do poder e do statussocial (ENGESTRÖM, 2009). Os sujeitos são os atores da atividade, cujo pontos de vista são escoIhidos como perspectiva de análise, e o objeto, o centro a partir do qual a atividade se desenrola: "[...] é convite à interpretação, à atribuição pessoal de sentido e à transformação social" (ENGESTRÖM, SANNINO, 2010, p. 6). 
A mediação entre esses elementos e também entre os diferentes sistemas de atividade que coexistem num determinado grupo social se faz possível pelas ferramentas culturais, materiais ou imateriais, aí existentes. A definição de sistema de atividade será adiante retomada, com mais detalhes.

- caráter coletivo, entendido como a mediação social entre sujeitos envolvidos numa atividade, é pródigo, assim, de conflitos de valores, de emoções, de objetivos, dentre outros - e se mostra essencial àquilo que Engeström denomina por "expansão da atividade." Essa concepção é própria da sua abordagem teórica e pretende significar a transformação, a ampliação, nos sistemas de atividades desenvolvidas num grupo social, movida pela tomada de consciência dos sujeitos, quanto às contradições vigentes nesse sistema. $\bigcirc$ conceito de contradição, empregado por Engeström (2009), pode ser entendido como a percepção (a tomada de consciência) das tensões estruturais historicamente acumuladas, quer no interior de um sistema de atividade, quer entre sistemas de atividades. A capacidade de reflexão é considerada a atividade direcionada a problematizar a realidade, favorecendo a emersão das contradições, forçando a novas mediações.

Na visão de Hartley (2012), a Teoria Histórico-Cultural da Atividade, de maneira geral, e as proposições de Engeström, em particular, apresentam limitações para analisar as relações de poder verticalizadas, que existiriam nas práticas sociais institucionalizadas, como naquelas escolares. A razão dessa limitação estaria na ênfase posta na consideração das relações horizontalizadas, vigentes na divisão do trabalho, em detrimento daquelas verticalizadas, presentes nas relações de poder, que permeiam a divisão do trabalho. Contudo, pondera-se aqui que ambas as vertentes teóricas criticadas por Hartley constituem-se em modelos abertos, centrados no estudo das contradições existentes nos sistemas de atividade humanos. A partir dessa ideia, pode-se traçar análises críticas também das relações de poder, entendendo-as como difusamente perpassando todos os elementos de um sistema de atividades, não sendo necessário e tampouco recomendável, sob pena de realizar reducionismos e centrar-se em um único aspecto.

A nosso ver, o modelo de sistema de atividade, apresentado por Engeström oferece uma base conceitual que permite a distinção entre as ações individuais (direcionadas para os objetivos) e a atividade coletiva (orientada para o motivo e influenciada histórica e culturalmente). Ademais, sinaliza a 
possibilidade de entendimento dos movimentos entre as ações individuais e coletivas por meio da materialização das interações entre os sujeitos/ grupo, enquanto mediadas pelos artefatos e outras ferramentas culturais. Esses movimentos são dinâmicos, tensionais e estabelecem entre si relações de desenvolvimento contínuo, indicando mudanças nas perspectivas dos sujeitos, como consequência de aprendizado, culminando em possibilitar tentativas de reorganizar e solucionar as contradições percebidas, presentes no sistema de atividade. As mudanças contínuas, a reelaboração da atividade e a constante interação e mediação entre os elementos da atividade, num processo incessante de construção e reconstrução, representa uma zona de desenvolvimento, visto que abrem caminho para a futura alteração da atividade (ENGESTRÖM, 1999a).

Assim, pelo fato de proporcionar um embasamento teórico que prioriza a diversidade e a multiplicidade inerente às atividades humanas, fundamental,entende-se, para o objeto tratado neste artigo, a necessidade de proceder a uma análise circunstanciada acerca da vertente da Teoria da Atividade proposta por Engeström. A questão a seguir é, pois, bastante pertinente: Quais as perspectivas abertas por essa abordagem para se pensar numa educação universitária como bem público, dentro de uma ética do cuidado?

\section{A expansão da atividade como estratégia formativa no ensino superior: possibilidade do educar para a ética do cuidado?}

Na perspectiva da Teoria Histórico-Cultural da Atividade, como teorizada por Engeström, as organizações sociais, igualmente às instituições de ensino superior, são compreendidas como comunidades de práticas, que regulam e gerenciam tensões, dilemas e conflitos, entre indivíduos, grupos de indivíduos e sociedade. Como esses dilemas e conflitos se interconectam, e emergem de um sistema de atividades, como os sujeitos lidam com tais dilemas e conflitos, como as soluções são mediadas e as contradições levantadas, e como se relacionam com propósitos e ações voltados a atingir estados de maior bem-estar, tanto para o coletivo como para os sujeitos individuais, são perspectivas a ser exploradas nessa linha teórica. É uma 
abordagem que se põe como referencial para a construção do conhecimento criativo, a partir de uma abordagem histórica, com base nas categorias de contradição interna, objeto da atividade e transformação dessa atividade.

Contrariando posições de influência positivista, a proposição postulada por Engeström (1999, 1999a) retoma a essencialidade de se compreender que o móvel fundamental para a formação conceitual do pensamento humano é o envolvimento do sujeito com o objeto orientado à atividade, compreendida, em sua natureza sociocultural, como, seminalmente, teorizado por Leontiev. Apoiando-se no materialismo histórico como base epistemológica, negando a separação sujeito-objeto-atividade, Engeström entende que as relações estabelecidas, nessa tríade, são dialeticamente configuradas. $\bigcirc$ objeto de uma atividade é algo já presente na cultura dos grupos sociais, e a sua eleição como objeto dessa atividade é dependente da interpretação em relação às necessidades de transformações, que devem ser feitas no entorno, possibilitando a sobrevivência. Sujeitos-objetos-atividade humana coevolvem, constituindo um sistema de atividade. Por sistema de atividade entende-se, então, o processo de envolvimento dinâmico entre a produção material de ferramentas culturais, as trocas sociais entre sujeitos, voltadas para um determinado objeto, mediadas por essas ferramentas, e os mecanismos individuais e coletivos de regulação tanto da produção quanto das trocas entre os sujeitos (ENGESTRÖM, 2009).

Engeström (2009) assevera que a criação de novos conhecimentos e novas formas de pensar somente é possível de emergirem nível das forças contraditórias, presentes nas atividades humanas. A contradição primária, em qualquer sistema de atividade existente numa sociedade de matriz capitalista, está entre a atribuição do valor de uso e do valor de troca vigente em cada um dos componentes da atividade. Quando essa contradição original é interpretada como tal, por exemplo, a mudança na atribuição do valor de uso advindo da criação de novas ferramentas culturais, colocando em xeque aquelas já existentes, a atividade e seu contexto mudam, o sistema se move de um estado relativamente estável para um estado de crise, não articulado, e daí para um estado de contradições secundárias, crescentemente agudas, entre os elementos da atividade. Isso "desestabiliza" ainda mais este sistema de atividade, empurrando-o para estados de criticalidade. 
Escapando da teleologia de que a necessidade é que cria motivo para a atividade, Engeström (1999), seguindo Leontiev (1978), afirma que a necessidade somente motiva a busca por objetos que possam mediar a atenção a estes, o que envolve reinterpretar a configuração cultural já constituída. Quando um objeto é bem sucedidamente encontrado (reinterpretado a partir da cultura como adequado às necessidades), ele se torna um motivo para a atividade. Origina-se, dessa forma, um solo fértil para a inovação nas ferramentas culturais (na forma de concebê-las, utilizá-las, conjugá-las...) e nos padrões de interação dos sujeitos da atividade entre si, com essas ferramentas e com a própria atividade.

Numa promoção da transformação do quadro cultural de referência mais generalizado, do qual as contradições originalmente emergiram, surge, então, a elaboração de contradições mais profundas, agora entre o modelo mais generalizado, modelo "velho", e o modelo "novo", chamadas de contradições terciárias; que tendem a levar a transformações no modelo "velho". A substituição dos modelos gera, por sua vez, contradições quaternárias, no sentido de que os sistemas de atividade que rodeiam aquele a partir do qual se originaram as contradições primárias, também começam a elaborar contradições, movidas pelo acentuar das diferenciações no sistema de atividade que se modificou, gerando um novo ciclo de transformações (ENGESTRÖN, SANNINO, 2010).

Engestron denomina esse movimento de transformação em um sistema de atividade de "expansão da atividade", processo histórico pelo qual ocorrem modificações e ampliações na forma das práticas sociais institucionalizadas num grupo social. Nesse processo, interagem e coevolvem a aprendizagem individual e coletiva, o desenvolvimento cognitivo dos sujeitos e do grupo, bem como o desenvolvimento das ferramentas e artefatos culturais e das formas de organização social.

A criação do conhecimento e a expansão da atividade, que o impulsiona, podem se tornar uma atividade colaborativa consciente, que se inicia quando os sujeitos começam a questionar conceitos e práticas vigentes. Esse questionamento deve voltar-se para as raízes das contradições existentes nos sistemas de atividades, elaboradas quando os sujeitos problematizam as condições de vida (as condições de bem-estar, ou de bem-viver) disponibilizadas 
a esses sujeitos pela própria configuração socioeconômica vigente na cultura geral.

Considera-se, aqui, acompanhando a teorização de Engeström, que uma perspectiva didática visando pensar o ensino superior como bem público, passa, necessariamente, por explorar as contradições existentes no fazer universitário, em todas as suas esferas. No que se refere aos aspectos didático-pedagógicos dessa formação, tais contradições podem ser exploradas refletindo-se em duas categorias centrais ao pensamento do autor em tela: a) a diversidade de concepções de realidade existente nos grupos de sujeitos que, engajados em sistemas de atividades vigentes no ensino superior, se constituem como uma força desenvolvimental, visto que, dessa diversidade, emergem conflitos, que apontam para a problematização da realidade em suas contradições e b) a polifonia, a multiplicidade de vozes existente nessa diversidade, que impulsiona a comunicação transformadora entre sistemas de atividades.

Como alertado por Engeström (1999), as contradições primárias não são passíveis de ser modificadas, pois toda atividade humana está intrinsecamente imbuída de um valor de uso e de um valor de troca, que se antagonizam. Pensando então nas contradições secundárias, geradas a partir dessas primárias, cuja problematização pode promover a expansão transformadora no sistema de atividade, elaborou-se o esquema abaixo. Nele, apresenta-se uma exemplificação de contradições secundárias, presentes entre os elementos de um sistema de atividade, que poderiam ser encontradas nos aspectos didático-pedagógicos da formação do estudante, pensando em como obstaculizam tal formação no âmbito de uma ética do cuidado. Observa-se que, na categoria "sujeitos", é representada a perspectiva a ser adotada por eles, visando alcançar o objetivo a que se propõe. 


\section{Figura 2}

\section{Contradições secundárias no sistema de atividade didático-pedagógica}

\begin{tabular}{|l|} 
Ferramentas culturais \\
"recursos tecnológicos atuais, que \\
favorecem o acesso ao conhecimento \\
para além da figura do \\
professor/instituição escolar; \\
"epistemologia positivista e cartesiana:
\end{tabular}

\section{Sujeitos}

"conhecimento é construído pelos sujeitos: seu domínio é social, nãoé posse individual;

"sujeitos constroem e modificam a realidade conforme atuam sobre esta: "Papel ativo e crítico do aluno na construção do saber:

"professor como "colaborador";

"professor como livre-pensador.

Divisão do trabalho *hierarquia rígida das funções didático-pedagógicas com o professor colocando-se como o detentor do saber/verdade e o aluno colocado como depositário e reprodutor deste saber

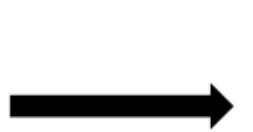

\section{Objeto}

"aluno como cliente, formação como transação quase-comercia no "capitalismo acadêmico."

Comunidade
"questionamentos sobre a ética
profissional e a validade do
conhecimento acadêmico -" "A
quem serve o conhecimento?";
"solicita profissionais que atendam às
necessidades da sociedade, de
forma ética e competente; superior
"espera-se que o ensino sue
garanta/melhore a empregabilidade
e a qualidade de vida.

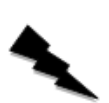

"exigência institucional e dos empregadores para formar na

lógica da eficiência produtiva; "valor de troca do conhecimento $=$ valor de uso imediato, técnico-científico.

Fonte | Arquivo pessoal das autoras (2014)

Conforme observado na esquematização acima, o modelo proposto por Engeström pode ser um instrumento para analisar as contradições num sistema de atividade, visando à melhor compreensão e eventual transformação. Em relação ao ensino superior e à formação do estudante na ideia de bem público, esse modelo permite analisar contradições relevantes, que, contemporaneamente, se mostram presentes nas instituições universitárias. Consideramos que tais contradições têm por base uma crise identitária da Universidade em 
relação a qual deve ser a sua missão frente às demandas da sociedade atual. E mesmo na formulação de quais seriam, afinal, tais demandas.

A partir das contradições secundárias, acima expostas, poderiam ser levantadas contradições terciárias, ou seja, aquelas que emergem dos sistemas de atividades, como, por exemplo, entre o aspecto didático-pedagógico da formação universitária e as primeiras práticas profissionais, na esfera dos campos de estágio. Como os conhecimentos teóricos e práticos desenvolvidos na formação do estudante se relacionam aos requerimentos da vida profissional? $\bigcirc$ aluno se mostra capaz de agir no âmbito de uma ética do cuidado? Essa vem sendo uma prioridade na sua formação? Como a ausência lou a presença) desse elemento formativo influencia a sua prática?

As contradições aqui indicadas, além de outras, originam-se na contradição primária quanto ao valor de uso e o valor de troca que o conhecimento adquire na sociedade atual. E que se desdobram na exigência produtiva, por parte dos órgãos de financiamento, em relação às instituições universitárias, fomentando a "tecnicização" e a burocratização de suas ações, a formação para o "mercado", a influência da tecnologia na construção e divulgação do saber, as questões éticas, e a própria questão da autonomia da universidade. Gerando conflitos e tensões que não se "esvaem", por si só, requerem uma "solução", no âmbito do sistema de atividade; não podendo ser ignoradas.

É preciso observar que, apesar do potencial que as contradições têm para promover transformações em um sistema de atividade, favorecendo sua expansão e complexificação, isso nem sempre ocorre como uma decorrência "natural" da dinamicidade desse sistema. A força das contradições pode acabar por promover, inversamente, a involução de um sistema de atividade. Por outro lado, para que as contradições levem à inovação, à emergência de um novo conhecimento, de novas formas de atividade, sua resolução não pode acontecer, somente, em nível individual, visto que é, no movimento entre os motivos, as formas de ser dos sujeitos individuais e aquelas do entorno social coletivo, que as contradições se originam, primariamente (MURPHY, RODRIGUEZMANZANARES, 2008). Para que as contradições se tornem efetivas como móvel para a mudança, é preciso que elas sejam abordadas de maneira a descortinar os motivos daquele(s) sistema(s) de atividade(s), entendidas em sua natureza coletiva, sócio-histórica, favorecendo a emersão de um novo objeto, que se constituirá no móvel para a transformação: a expansão do sistema de atividade. Tal expansão gera novos instrumentos culturais, dentre eles, novos 
conceitos e teorizações sobre a realidade, e, correlatamente, novas formas de ação dos sujeitos sobre os objetos, entre sujeitos, novas regras, outras relações com a comunidade.

Engeström (2001) sugere um ciclo para o desenvolvimento de ações de aprendizagem, que, partindo das contradições entre os elementos e um sistema de atividade, e/ou entre sistemas de atividades, podem conduzir à sua expansão:

\section{Figura 3}

\section{Ciclo de expansão da atividade}

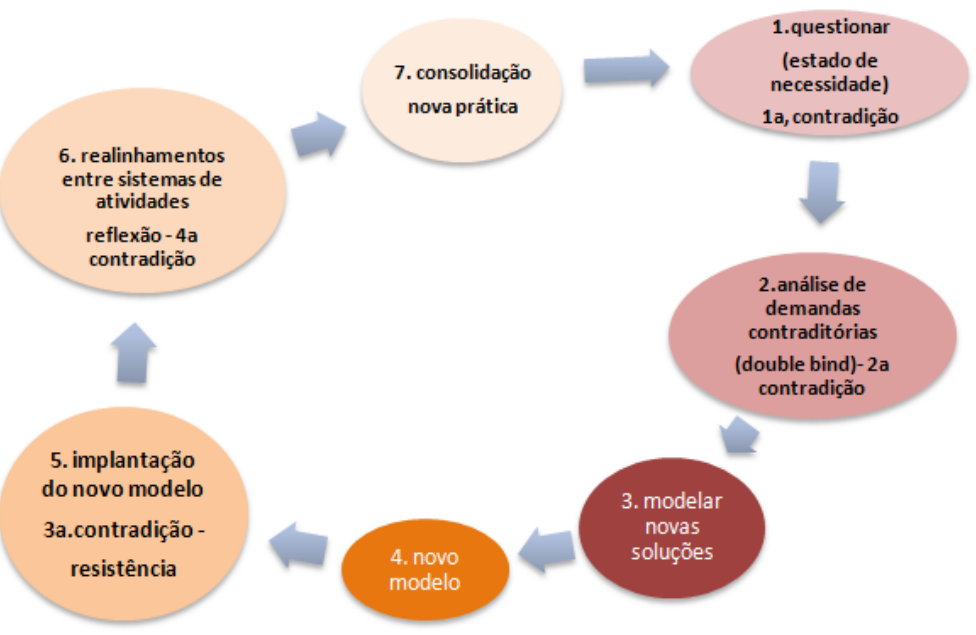

Fonte | Engeström (2001)

Em relação às contradições apontadas na Figura 2, a questão a seguir é bastante pertinente: como essas poderiam ser explicitadas de modo a favorecer o potencial de expansão do sistema de atividade didático-pedagógica no ensino superior, visando à formação do estudante para pensar o bem público? Na tentativa de responder a essa questão,organizou-se a Figura 4 abaixo. 


\section{Figura 4}

\section{Ciclo de expansão da atividade visando a formação para a responsabilidade social}

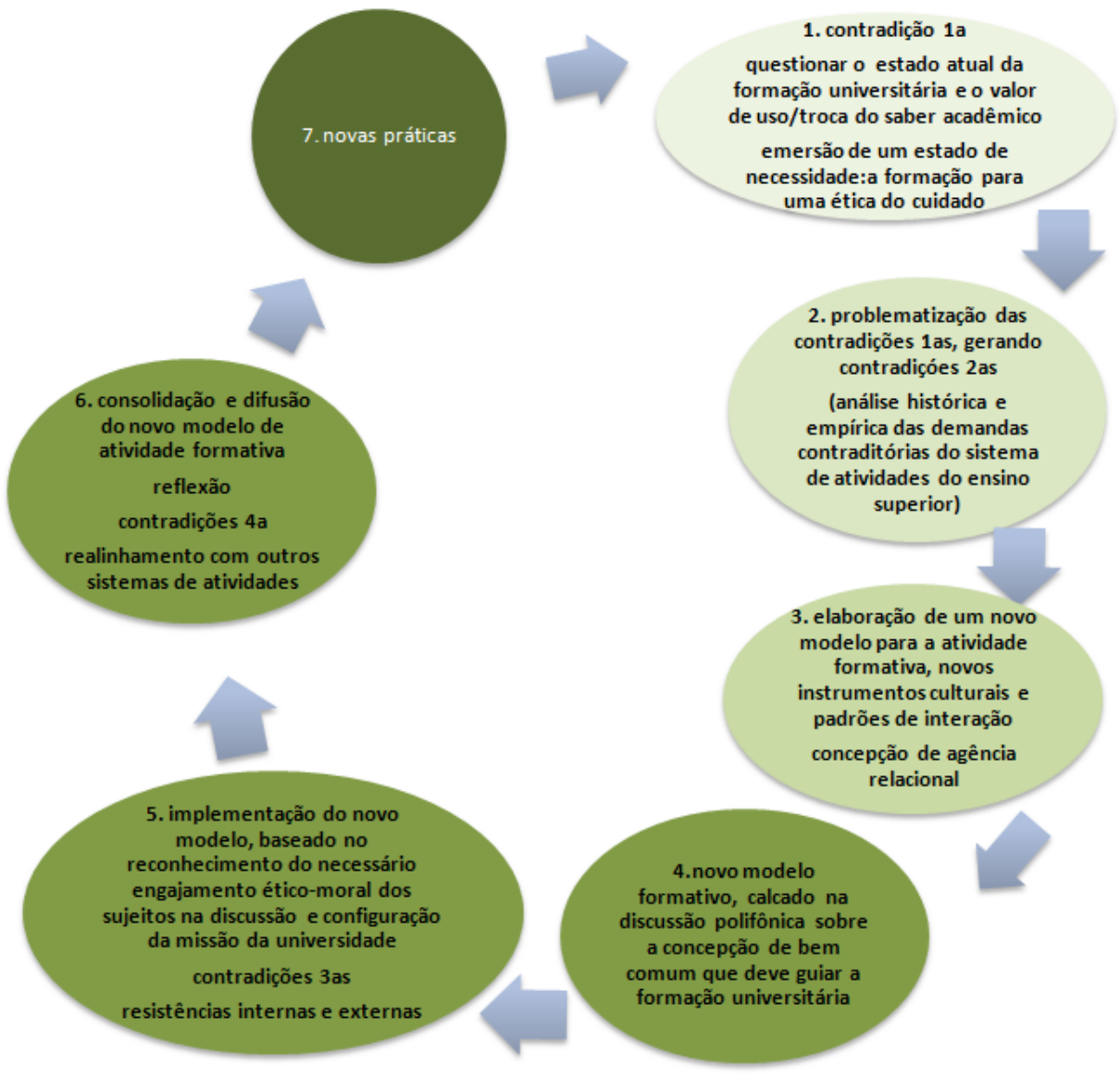

Fonte | Arquivo pessoal das autoras (2014)

A esquematização propõe, como contradição primária, aquela que reside na raiz do objeto aqui analisado: a formação do estudante universitário para a responsabilidade social, o valor de uso e o valor de troca do conhecimento acadêmico. Quais os conhecimentos valorados, como vêm sendo produzidos, por que, por quem, fomentando quais interesses, em detrimento de quem? $\bigcirc$ questionamento quanto às raízes históricas dessa contradição 
impulsiona o desdobrar do ciclo de expansão da atividade formativa desse estudante na direção aqui discutida.

Em seu substrato, e, de em acordo com os fundamentos que sustentam a perspectiva da ética do cuidado, as ações propostas, nesse ciclo,baseiam-se no desenvolvimento de um sentido de intencionalidade colaborativa dos sujeitos em relação às suas comunidades, e vice-versa. Isso requer, concomitantemente, uma perspectiva de agência relacional, definida como a capacidade dos sujeitos para alinhar pensamentos e ações na problematização e interpretação dos problemas do cotidiano, criando e reunindo recursos para responder a estes (EDWARDS, 2009). O ciclo mencionado acima deve ser entendido por essa premissa.

Assumir essas etapas na ampliação de um sistema de atividade requer romper com a lógica bancária (FREIRE, 1987) de que o processo de ensino-aprendizagem se estrutura no acúmulo de conteúdos, tidos como neutros e anhistóricos. Essa tendência que, embora constantemente criticada em diversas correntes e discursos educacionais, se exacerba em face da reificação da técnica e da eficiência produtiva como cerne da formação profissional (e pessoal) acadêmica.Exige, também, (re)acender, nas ações didático-pedagógicas, a 131 necessidade de se criar ambientes de aprendizagem pautados no:

[...] contexto do criticismo los poderes de resistir, questionar, contradizer e debater), no contexto da descoberta (os poderes de experimentar, modelar, simbolizar e generalizar), e no contexto da aplicação social prática los poderes da relevância social e da imersão no conhecimento, o envolvimento na/da comunidade e a prática guiada). Este tipo de expansão no objeto da atividade sucede em quebrar 'o encapsulamento da aprendizagem escolar' [...] e assim implica na transformação de todo o sistema de atividade acadêmica (EDWARDS, 2009, p. 216 ).

Convém ressaltar que a discussão polifônica quanto ao que é o bem comum assume relevância no dinamismo do ciclo proposto. Permitir que determinados indivíduos ou grupos decidam pelos demais o que é bem comum, o que é justiça, o que é cuidar... contraria todo o exposto até aqui. Acompanhando o pensamento de Sen (1999), tais questões somente podem ser definidas com o reconhecimento do direito fundamental de cada um de se manifestarem relação a essas questões. É uma decisão coletiva, relacional, e é essa perspectiva 
que deve conduzir, por exemplo, a discussão quanto à missão hodierna do ensino superior e como esta deve ser levada a efeito.

A questão das contradições se apresenta no ciclo como um todo, diferenciando-se conforme a fase em que o processo se encontra. A expansão do sistema, como já exposto, se "alimenta" dos conflitos e insatisfações de professores, estudantes, famílias e comunidade acadêmica e extra-acadêmica, convidando-os a se unir aos esforços visando a uma transformação concreta da situação vivida.

\section{Considerações finais}

Desde o seu princípio, a Teoria Histórico-Cultural da Atividade foi pensada para ser uma abordagem dialética, propondo o estudo dos fenômenos humanos interligando o sujeito, individual e coletivo à estrutura econômico-social. Constitui-se, dessa forma, em uma vertente epistemológica apropriada para a produção do conhecimento em tempos de intensa transformação social.

Acompanhando a ideia central do pensamento da Teoria HistóricoCultural da Atividade, procurou-se transformar o mundo, de acordo com ele é interpretado, agindo em concordância com tais interpretações; é válido salientar que tanto a interpretação como a ação decorrente só são possíveis pelas ferramentas culturais de que dispomos, resultantes de um processo sócio-histórico de interpretação e transformação do mundo. Na vertente desenvolvida por Engeström, aqui explanada, isso ocorre no âmbito de um sistema, que muda através da expansão do objeto que constitui sua atividade-guia. $\bigcirc$ objeto se expande, se amplia, quando a variedade de interpretações disponíveis,e as contradições que se originam, são reveladas e exploradas. A expansão do sistema de atividade, por sua vez, impulsiona novas interpretações, a criação de novas ferramentas culturais, novas formas de interação social, novas perspectivas de análise para os sujeitos, em sua singularidade, desencadeando, assim, o seguimento de outras contradições, dando início a um novo ciclo de expansão.

Essa foi a vertente aqui buscada para se pensar numa perspectiva pedagógica no ensino superior voltada para a ética do cuidado e a reafirmação da educação como bem público. Considera-se, como fundamento dessa busca, a importância de se questionar como os processos de 
ensino-aprendizagem devem ser pensados para formar estudantes com uma mentalidade problematizadora em relação ao cotidiano e à sua complexidade social, ecológica, econômica, dentre outras, que apresentem proposições inovadoras, pautadas por um ideal de equidade e justiça social.

As Universidades, como aqui argumentado, não deveriam se preocupar somente com a produção e divulgação de conhecimentos, mas também procura articulá-los, travando uma discussão sobre o papel que tais conhecimentos assumem na construção e validação dos valores éticos e morais permeiam o viver social. Sem um propósito ético-moral claro,explícito, as instituições de ensino superior perdem o seu suporte social, gerando uma crise identitária quanto às suas finalidades e razões de existência. A defesa dessas instituições, enquanto fomentadoras do bem público, se baseia na concepção de que, dentre as responsabilidades da Universidade, está aquela de criar ambientes e práticas de aprendizagem que desenvolvam e disseminem a ideia da Educação como engajamento cívico, continuamente indagando: quais as crenças, valores e saberes que facilitam ou inibem a capacidade e a organização da Educação Superior para educar para o bem público? Quais forças, internas e externas às instituições universitárias, se interpõem na relação 133 ensino-aprendizagem e o envolvimento da comunidade acadêmica com o bem público? Que medidas podem ser propostas para construir e fortalecer um movimento de renovação humanista, como exposta ao longo deste artigo, na Universidade?

À guisa de conclusão,é importante aqui ponderar que a base teórica desenvolvida por Engeström, em conjunção com a abordagem da ética do cuidado, podem constituir-se em referenciais para a reflexão sobre as novas formas que o fazer universitário pode assumir, para melhor enfrentar os dilemas da sociedade contemporânea. Obedecendo aos princípios da Teoria Histórico-Cultural da Atividade, é preciso agir para transformar, e transformar para melhor compreender, já que a atividade humana não pode ser compreendida, abstratamente, em um vácuo, mas somente acompanhando a dinâmica da vida. As esquematizações, propostas na expansão do sistema de atividade,contribuem para provocar um movimento transformador no fazer universitário, aqui pensado em relação aos seus aspectos didático-pedagógicos.Assim, é possível descortinar como esse fazer vem se desenvolvendo, as suas contradições, objetos, regras, papel dos sujeitos, da comunidade, etc. Importa observar, contudo, que, na ideia de transformação, não está explícita 
aquela de uma fórmula, ou de prescrições. Antes, deve ser entendida como um processo de questionar criticamente práticas cotidianas, conferindo-lhes outros significados, outros valores, mobilizar o pensamento individual e coletivo quanto à qualidade das relações pessoais, oxigenando o tramar da realidade. Esse é o caminho para que as instituições universitárias se posicionem como espaços de resistência quanto à mercantilização da vida, que parece vigorar na sociedade contemporânea.

\section{Referências}

BOK, Derek Curtis. Beyond the Ivory tower: social responsibilities of the Modern University. USA: Harvard College, 1982.

BOURDIEU, Pierre. O poder simbólico. Rio de Janeiro: Bertrand Brasil, 1989.

COX, Robert. The global political economy and social choice. In: COX, Robert; SINCLAIR, Timothy J. Approaches to world order. Cambridge: Cambridge University Press, 1996.

EDWARDS, Anne. Agency and Activity Theory: from the systemic to the relational. In: SANNINO, Annalisa; DANIELS, Harry; GUTTIEREZ, Kris (Ed.). Learning and expanding with activity theory. Cambridge: Cambridge University Press, 2009.

ENGESTRÖM, Yriö. Activity Theory and Individual and Social Transformation. In: ENGESTRÖM, Ritva; VÄHÄAHU, Taria. Activity theory and individual and social transformation. Cambridge: Cambridge University Press, 2009.

Expansive Visibilization of Work: An Activity-Theoretical Perspective. Computer supported cooperative work, Dordrecht, v. 8, p. 63-93, march, 1999a.

Expansive learning at work: toward an activity theoretical reconceptualization. Journal of Education and Work, London, v. 14, n. 1, p. 133-156, feb. 2001.

From learning environments and implementation to activity systems and expansive learning. Actio: An International Journal of Human Activity Theory, Kansai, v. 2, n. 2, p. 17-33, oct. 2009.

ENGESTRÖM, Yriö;SANNINO, Annalisa. Studies of expansive learning: foundations, findings and future challenges. Educational Research Review, Atlanta, v. 5, p. 1-24, jan. 2010. 
Discursive manifestations of contradictions in organizational change efforts: A methodological framework. Journal of organizational change management, Bingley, v. 24, n. 3, p. 368-387, may 2011 .

FREIRE, Paulo. Pedagogia do oprimido. 17. ed. Rio de Janeiro: Paz e Terra, 1987.

GARCÍA, Alejandra A. La ética del cuidado. Revista Aquichan, Bogotá (Colombia), v. 4, n. 4, p. 30-39, out. 2004.

GILLIGAN, Carol. In adifferent voice. Cambridge: Harvard University Press, 1982.

GOOD, Graham. Humanism betrayed: theory, ideology and culture in the contemporary university. Canada: McGill-Queen's University Press, 2001.

HARTLEY, David. Education and the culture of consumption: personalisation and social order. USA: Routledge, 2012.

HELD, Virginia. The ethics of care: personal, political and global. Oxford University Press, 2006.

HESPANHA, Pedro. The dynamics of globalization: social crisis and conflict in the portuguese rural areas. Centro de Estudos Sociais, Coimbra, dez. 1986.

LEONTIEV, Aleksei Nikolaevich. O desenvolvimento do psiquismo. São Paulo: Moraes, 1974.

Actividad, conciencia y personalidad. Buenos Aires: Ciências delHombre, 1978.

The problemofactivity in psychology. In: WERTSCH, James (Ed.) The conceptofactivity in sovietpsychology. New York: M. E. Sharpe Inc., 1979.

LINGARD, Bob; NIXON, Jon; RANSOM, Stuart. Transforming learning in schools and communities: the remaking of education in cosmopolitan societies. London: Continuum Books, 2008.

MAGATTI, Mauro. Il potere istituente del la società civile. Bari: Laterza, 2005.

MURPHY, Elizabeth; RODRIGUEZ-MANZANARES, Maria A. Using activity-theory and its principle of contradiction to guide research in educational technology. Australasian journal of education, Sidney, v. 24, n. 4, p. 442-457, aug. 2008.

NATALE, Samuel; LIBERTELLA, Anthony; HAYWARD, Geoff. Higher education in crisis: the corporate eclipse of the university. New York: Global Publications, 2001. 
$\mathrm{NIXON}$, Jon. Interpretative pedagogies for higher education - Arendt, Berger, Said, Nussbaum and their legacies. London: Continuum Books, 2012.

SANTOS, Boaventura de Sousa. Pelas mãos de Alice: o social e o político na pós-Modernidade. 7.ed. Portugal: Afrontamento, 1999.

SEN, Amarthya. Development as Freedom. Uk: Oxford University Press, 1999.

SILVERIO, Maria. BRICS: desigualdades sociais nos países emergentes. Observatório das desigualdades, Lisboa: Instituto Universitário de Lisboa. 2014. Disponível em:http://observatoriodasdesigualdades. cies. iscte. $p t /$ index. jsp?page=projects\&id=123. Acessoem: 10 jan 2014.

WALKER, Melanie; NIXON, Jon. Reclaiming universities from a Runway World. Society for Research into Higher Education/Open University, 2004.

Profa. Dra. Maria Luísa Bissoto

Centro Universitário Salesiano de São Paulo | Americana

Campus Maria Auxiliadora

Programa de Pós-Graduação em Educação Sociocomunitária

Grupo de Pesquisa Conhecimento e Análise das Intervenções na Práxis

Educativa Sociocomunitária | CAIPE | Vinculado ao CNPq

E-mail | malubissoto@yahoo.com

Profa. Ms. Maria Luiza Vechetin Begnami

Centro Universitário Hermínio Ometto | UNIARARAS | Araras

Grupo de Pesquisa Conhecimento e Análise das Intervenções na Práxis

Educativa Sociocomunitária | CAIPE | vinculado ao CNPq

E-mail | luizabegnami@gmail.com

Recebido 2 abr. 2014

Aceito 21 nov. 2014 